\title{
Recent Topics of Research and Development in Continuous Casting
}

\author{
Tooru MATSUMIYA \\ Technical Development Bureau, Nippon Steel Corporation, 20-1 Shintomi, Futtsu 293-8511 Japan.
}

(Received on February 7, 2006; accepted on May 29, 2006)

\begin{abstract}
Three major issues in continuous casting are nonmetallic inclusions, cracking and segregation. By the application of electromagnetic stirring (EMS) in mold the inclusion entrapment by the growing initial solid shell is hindered and the number of inclusions near the surface of slabs is much reduced. By the application of level magnetic field (LMF) the downward liquid flow induced by the exit flow from submerged entry nozzle is much decelerated and the entrapment of large size inclusions inside the slabs is eliminated, which otherwise cause inner defects. Electromagnetic casting (EMC) prevents from the formation of oscillation mark and hook mark, concomitantly eliminates the entrapment of inclusions and bubbles at the hook mark and also prevents from the formation of surface depression and longitudinal surface cracking in hypo-peritectic steels. Resonance-like unsteady bulging with oscillation of molten metal level in mold causes internal cracking and can be prevented by unequally spaced support rolls. Macrosegregation can be reduced by the proper reduction of casting thickness or, in the case of bloom, the minimization of the size of equiaxed solids, which can be realized by the application of EMS.
\end{abstract}

KEY WORDS: nonmetallic inclusions; casting cracking; solidification segregation; electromagnetic stirring; electromagnetic break; electromagnetic casting; unsteady bulging; soft reduction.

\section{Introduction}

Three major issues in continuous casting are nonmetallic inclusions, cracking and segregation. The recent topics of the research and development on these issues are discussed in this paper. Regarding nonmetallic inclusions the reduction of inclusion number density and the modification of inclusions for the removal of their harmful effect or their utilization can be mentioned. Examples of the latter are deformable inclusions in steel tire cords and stainless steel wire $^{1)}$ and oxides metallurgy in steels. ${ }^{2)}$ As the former examples the metal flow control in the mold by the application of electromagnetic force are discussed in this paper: EMS, LMF and EMC. Among them, EMC has been developed as electromagnetic casting project of JRCM, ${ }^{3)}$ which is financially supported by Ministry of Economy, Trade and Industry of Japan and clarified to also solve the problem of the longitudinal surface cracking of hypo peritectic middle carbon steels. Thermal and transformation-induced deformation, bulging (steady bulging), bending and unbending of casting has been studied to clarify the mechanism and find the prevention measure of casting cracking. In addition to them unsteady slab bulging has been paid attention recently, which is resonant with the mold liquid level oscillation. ${ }^{4)}$ Its mechanism and countermeasure are discussed here. For the prevention of macrosegregation soft reduction of slab thickness near the crater end, which compensates the thermal contraction and solidification shrinkage in order to prevent from the suction and entrapment of solute enriched residual liquid. For the size reduction of the macrosegregation in the case of bloom, the size reduction of the equiaxed solids by the application of EMS is also considered effective. They are also discussed here.

\section{Reduction of Nonmetallic Inclusions}

\subsection{Electromagnetic Stirring in Mold}

The liquid flow induced by the application of EMS in mold imposes Saffman force on nonmetallic inclusions, which hinders the entrapment of inclusions by the growing initial solid shell. Figure 1 shows the relation between the maximum diameter of alumina inclusions and the velocity of molten steel induced by EMS. ${ }^{5)}$ When the inclusion sep-

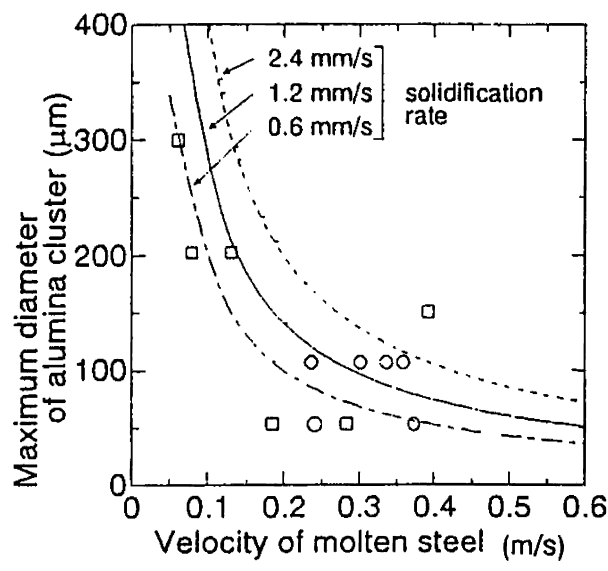

Fig. 1. Influence of velocity of molten steel on the maximum diameter of alumina cluster. ${ }^{5}$ 

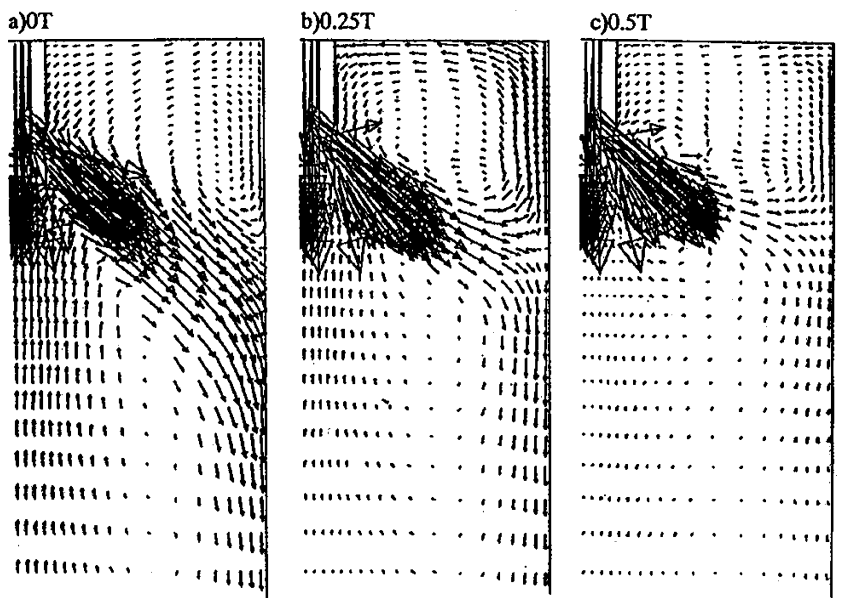

Fig. 2. The calculated flow vector distributions in the mold with various magnetic fields. ${ }^{6}$

aration velocity induced by the Saffman force is greater than solidification front velocity of the initial solid shell, the inclusion is considered not be entrapped. In the same figure the limits of entrapment based on this consideration are also drawn at various solidification rate. Since the larger the inclusion the lager the Saffman force imposed on the inclusion in the same flow field, larger inclusions are prevented from entrapment with lower flow velocity. It shows that inclusions with the diameter of $100 \mu \mathrm{m}$ can be washed out by the flow of $0.3 \mathrm{~m} / \mathrm{s}$.

\subsection{Level Magnetic Field}

By the application of a static magnetic field in the thickness direction over the width of slab, the velocity of liquid flow ejected from two side holes of a submerged entry nozzle is reduced and the depth where the following down stream reaches becomes shallower (Fig. $\left.\mathbf{2}^{6}\right)$. Therefore it increases the opportunity for inclusions and bubbles to float up to the top mold flux. As the result, their entrapment inside the slabs is prevented, which otherwise causes inner defects of slabs.

\section{Electromagnetic Casting}

In EMC a solenoid coil horizontally surrounds a casting mold and alternative current is applied to the coil. Lorenz force made by the vertical magnetic field and horizontally circulating secondary current induced in the casting always directs inward even when the direction of the alternative current is reversed. That is, pinch force is induced all the time to the initial solid shell and supports the shell (Fig. 3). The gap between the initial solid shell and the mold surface is enlarged and heat extraction from the mold is reduced, that is, mild cooling is realized. Due to this mild cooling the solidification growth of initial shell over the curved meniscus is prevented and the pressure fluctuation in the mold-shell gap associated to mold oscillation is reduced because of the enlargement of the gap. As a result, formation of oscillation mark and hook mark is prevented (Fig. 4) and concomitant entrapment of nonmetallic inclusions and bubbles at the hook mark is also eliminated. In addition to the disappearance of oscillation mark, the deformation of initial solid shell due to the contraction associated to the

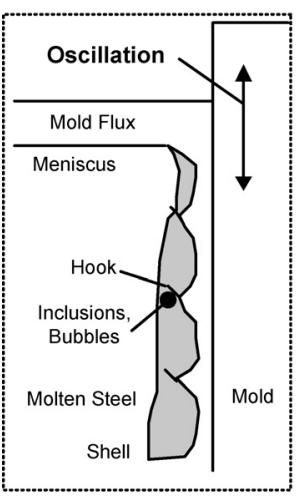

Conventional CC

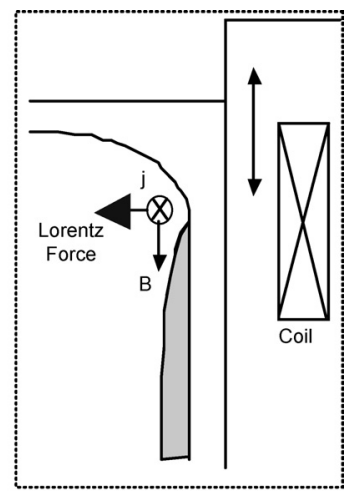

EMC
Fig. 3. Principle of electromagnetic casting. ${ }^{8)}$
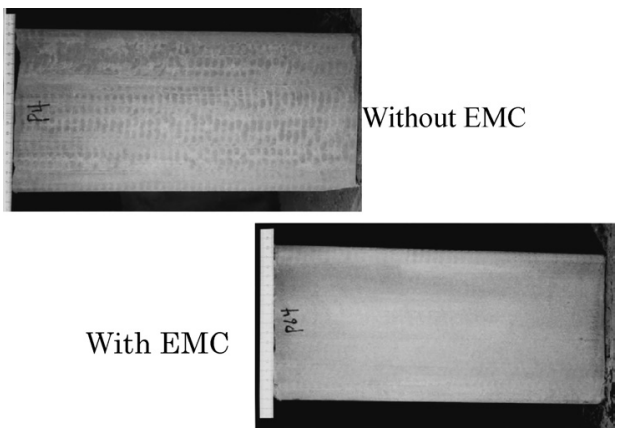

Fig. 4. Comparison of surface appearance of billets cast with and without electromagnetic casting. ${ }^{8}$ )

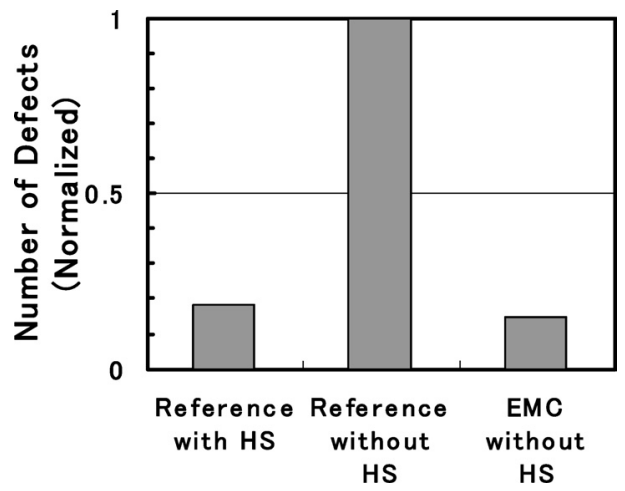

Fig. 5. Number of defects in the products $\left.{ }^{8}\right)(0.1 \% \mathrm{C}$ steel. HS: Hot Scarfing).

delta-gamma transformation in hypo-peritectic middle carbon steels ${ }^{7)}$ is also suppressed by the higher Ferro static pressure against weaker solid shell. Concomitantly, the surface depression and longitudinal surface cracking are also prevented. Because of the surface smoothness and the reduction of subsurface nonmetallic inclusions of slabs, the number of defect of products is much reduced. Even if hot scarfing is not applied to slabs cast with EMC, it is equivalent to that of the products from slabs with hot scarfing after cast without EMC (Fig. 5) ${ }^{8)}$

\section{Resonance-like Unsteady Slab Bulging with Oscilla- tion of Mold Liquid Level}

Once some of the slab bulging remains permanently molten metal is squeezed out upward when bumped part 


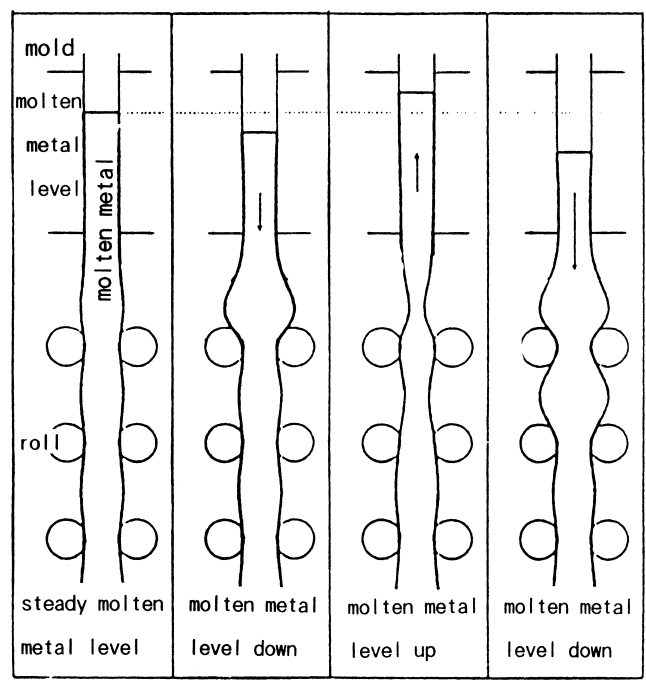

Fig. 6. Schematic diagram of mechanism of the start of resonance-like unsteady bulging. ${ }^{4}$

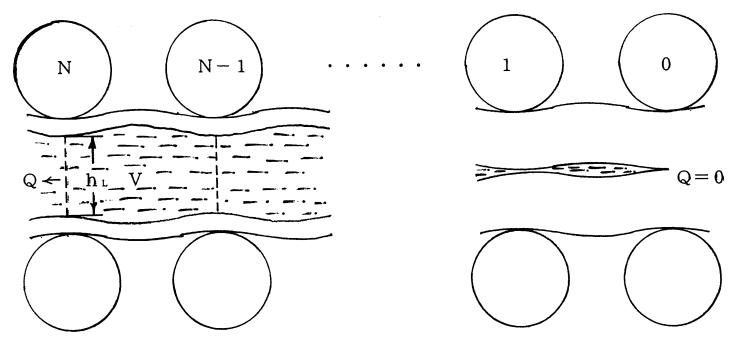

Fig. 7. Longitudinal cross-section of slab with liquid core at roll $N$ to roll $N-1$ and at the crater end. ${ }^{4}$

moves to roll gap and sucked in downward when concaved part moves to roll gap as shown in Fig. 6. The dynamical pressure is minimum (negative) when the bumped part is on the roll and maximum (positive) when the concaved part is on the roll gap due to the movement of molten metal, which is analyzed below. Therefore, the permanently remained bulging is enhanced by the repetition of this pressure oscillation and the oscillation of mold metal level gets larger and larger and exceeds the upper face of the mold, that is over flow occurs, in the extreme case.

Figure 7 shows the longitudinal cross-section of slab with liquid core and sign curved permanent bump on its surface. The liquid metal volume $V$ is calculated as Eq. (1) by the assumption of sign curve shape of the permanent bulging:

$$
V=\left\{h_{\mathrm{L}}+\delta \cos \left(2 \pi v_{\mathrm{c}} t / L\right)\right\} L w .
$$

where $h_{\mathrm{L}}$ : thickness of liquid metal at roll $N, \delta$ : amplitude of permanent bulging, $v_{\mathrm{c}}$ : casting speed, $t$ : time ( $t=0$ when concave part is on a roll), $L$ : roll pitch and $w$ : width of liquid metal at roll $N$. The roll number is counted from the crater end of the liquid core towards meniscus. When the same amount of permanent bulging exists in all roll spacing, the flux of liquid metal $Q$ at roll $N$ is obtained as follows:

$$
\begin{array}{r}
d V / d t=-\delta \cdot 2 \pi v_{\mathrm{c}} w \cdot \sin \left(2 \pi v_{\mathrm{c}} t / L\right) \\
Q \fallingdotseq N(-d V / d t) \ldots \ldots \ldots \ldots \ldots \ldots \ldots \ldots
\end{array}
$$
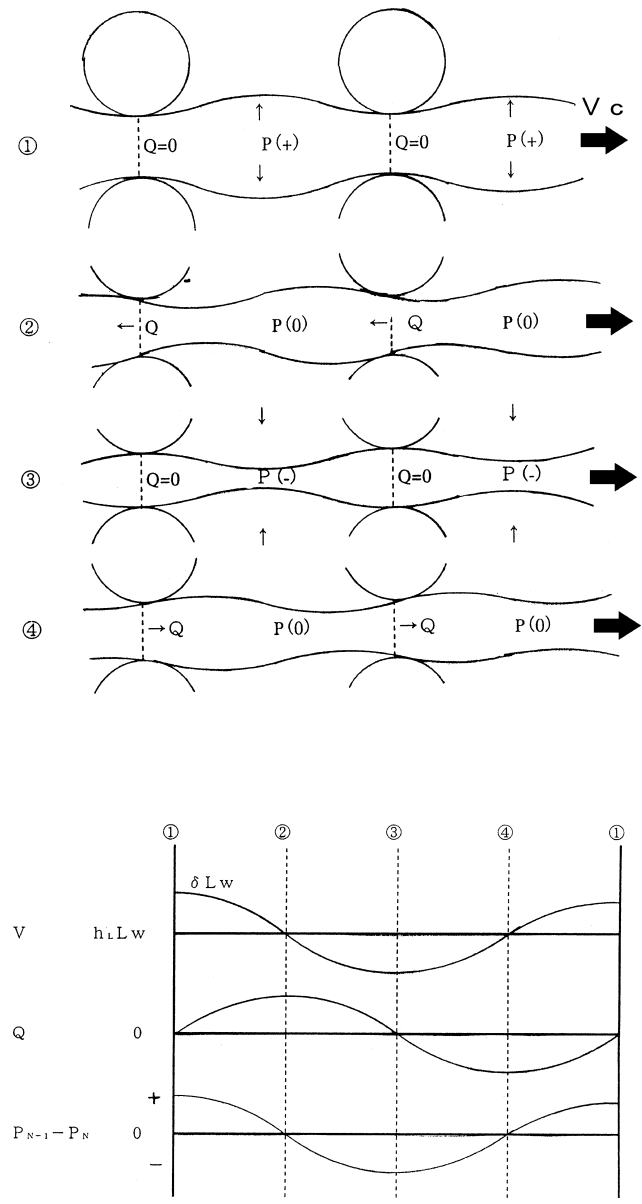

Fig. 8. Core liquid volume, molten metal flux and dynamic pressure increment between two adjacent rolls as functions of the position of the peak of permanent bump on slab surface. ${ }^{4)}$

Liquid velocity relative to casting speed $v_{\mathrm{L}}$ and acceleration $a_{\mathrm{L}}$ at roll $N$ are calculated as follows:

$$
\begin{array}{r}
v_{\mathrm{L}}=Q /\left(h_{\mathrm{L}} w\right) \ldots \ldots \ldots \ldots \ldots \ldots \ldots \ldots \ldots \ldots \ldots \ldots \ldots \\
\left.a_{\mathrm{L}}=d v_{\mathrm{L}} / d t=\delta\left(2 \pi v_{\mathrm{c}}\right)^{2} N \cdot \cos \left(2 \pi v_{\mathrm{c}} t / L\right)\right\} /\left(L h_{\mathrm{L}}\right) \ldots
\end{array}
$$

Since the acceleration comes from the dynamical pressure the following equation of force balance should be satisfied:

$$
\left(P_{N-1}-P_{N}\right) h_{\mathrm{L}} w=V \rho \cdot a_{\mathrm{L}}
$$

where $P_{N-1}$ and $P_{N}$ are dynamical pressure at roll $(N-1)$ and $N$, respectively, and $\rho$ is the liquid metal density. From Eqs. (1), (5) and (6), pressure increment between adjacent rolls is derived and from the sum of the increment the dynamical part of the pressure at roll $N$ is obtained.

$$
\begin{array}{r}
\left.P_{N-1}-P_{N} \fallingdotseq \rho \delta\left(2 \pi v_{\mathrm{c}}\right)^{2} N \cdot \cos \left(2 \pi v_{\mathrm{c}} t / L\right)\right\} / h_{\mathrm{L}} \\
P_{N}=\sum_{i=N+1}^{N_{\mathrm{E}}}\left(P_{i-1}-P_{i}\right) \ldots \ldots \ldots \ldots \ldots \ldots \ldots \ldots \ldots
\end{array}
$$

where $N_{\mathrm{E}}$ is equivalent roll number at meniscus. The liquid volume, metal flux and pressure increment is shown in Fig. 8 corresponding to the location of the bump of the permanent bulging. 
When the solid shell thickness $S$ is proportional to the square root of the time elapsed from meniscus $h_{\mathrm{L}}$ is calculated for a slab with thickness $H$ as follows:

$$
h_{\mathrm{L}}=H\left[1-\left\{\left(N_{\mathrm{E}}-N\right) / N_{\mathrm{E}}\right\}^{1 / 2}\right]
$$

Under the following conditions, dynamic pressure at the crater end is obtained: $\rho=7.3 \mathrm{~g} / \mathrm{cm}^{3}, \delta=0.1 \mathrm{~cm}, L=30 \mathrm{~cm}$, $H=5 \mathrm{~cm}$ and $S=25[\mathrm{~mm}](t[\mathrm{~min}])^{1 / 2}$. When $v_{\mathrm{c}}=10 \mathrm{~cm} / \mathrm{s}$ $(6 \mathrm{~m} / \mathrm{min}), N_{\mathrm{E}}=20$ and $P_{1}$ is approximately $3 \times 10^{5} \mathrm{~g} \cdot \mathrm{cm} / \mathrm{s}^{2} /$ $\mathrm{cm}^{2}$, i.e., $0.3 \mathrm{~atm}$. When $v_{\mathrm{c}}=16.7 \mathrm{~cm} / \mathrm{s}(10 \mathrm{~m} / \mathrm{min}), N_{\mathrm{E}}=33$ and $P_{1}$ is approximately $2.5 \times 10^{6} \mathrm{~g} \cdot \mathrm{cm} / \mathrm{s}^{2} / \mathrm{cm}^{2}$, i.e., $2.5 \mathrm{~atm}$. When $v_{\mathrm{c}}=33.3 \mathrm{~cm} / \mathrm{s}(20 \mathrm{~m} / \mathrm{min}), N_{\mathrm{E}}=67$ and $P_{1}$ is approximately $3.0 \times 10^{7} \mathrm{~g} \cdot \mathrm{cm} / \mathrm{s}^{2} / \mathrm{cm}^{2}$, i.e., $30 \mathrm{~atm}$.

In order to prevent from above mentioned resonance-like unsteady slab bulging, unequally spaced support roll arrangement is highly recommended, especially at the upper part of the caster where the shell is weak and apt to have permanent bump due to bulging. Intensive cooling is also recommended to strengthen the solid shell.

\section{Countermeasure of Macrosegregation}

\subsection{Soft Reduction of Slab Thickness}

It was found that sulfide shape control in anti-hydrogeninduced-cracking steels for line pipes by calcium addition is not successful in the case when the size of spot-like segregation is not enough reduced even when the calcium is properly added. ${ }^{9)}$ The spot-like segregation is formed as follows: The solute-enriched residual liquid is squeezed out by a negative pressure due to solidification shrinkage and thermal contraction and entrapped in a spot-like shape at the vicinity of the thickness center of slabs. Therefore, in order to prevent from the spot-like segregation formation, soft reduction of slab thickness is applied, which compensates the shrinkage and contraction.

However, on the other hand, if the rate of the reduction exceeds the rate of thermal contraction and solidification shrinkage, positive pressure is induced, which induces residual liquid movement in the opposite direction and results masrosegregation again. Figure 9 shows that the optimum reduction rate ranging from 0.78 to $0.86 \mathrm{~mm} / \mathrm{min}$ depending on slab thickness eliminates macrosegregation and $\mathrm{A}$ or $\mathrm{V}$ type macrosegregation is resulted otherwise. ${ }^{10)}$

In addition, thickness reduction after the solid fraction at the slab center exceeds a threshold, approximately 0.7 , when the residual liquid exists separately, is not effective for the elimination of macrosegregation, that is, it flattens spot-like segregation and some cases makes them continuous. Columnar structure is preferred to apply the reduction precisely to the shrinking region and make the reduction more effective.

Since slab bulging also induces liquid movement, closely spaced rolls are adopted to solve the problem of macrosegregation.

\subsection{Equiaxed Grain Refinements and Soft Reduction in Case of Blooms and Billets}

Equiaxed crystal zone in the center of bloom is required for prevention of bridging formation in brooms and billets, which causes severe $\mathrm{V}$ type segregation and macro porosity.

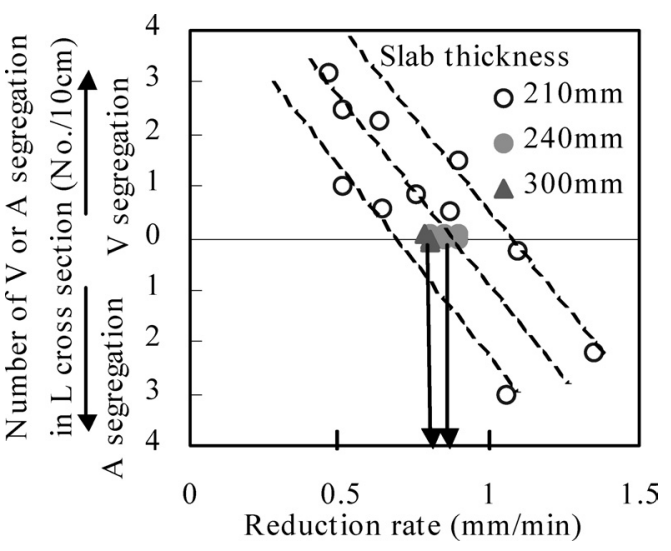

Fig. 9. Relation between number of $\mathrm{V}$ and $\mathrm{A}$ type segregation and reduction rate. ${ }^{10)}$

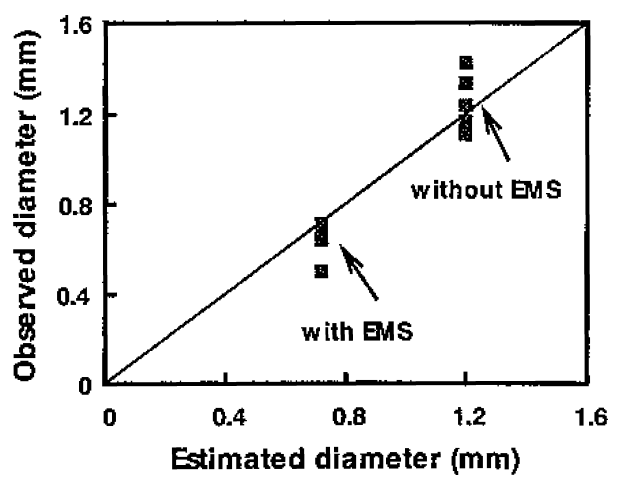

Fig. 10. Comparison of estimated diameter of equiaxed crystal with observed one, where the casting speed is $1.5 \mathrm{~m} / \mathrm{min}$ and superheat in tundish is $40 \mathrm{~K}^{11)}$

Equiaxed structure is obtained by the use of electromagnetic stirring in mold and at final solidification stage and low supper heat in poured steel. In addition, the application of soft reduction further reduces the diameter of spot-like macrosegregation. In the case of bloom, where the ratio of the width of unsolidified region to the total width at the reduction is smaller than in the case of slab, the optimum reduction rate is larger than that in the case of slab. ${ }^{10)}$

Since reducing the size of equiaxed crystal can reduce the segregation diameter, the study for the prediction of the grain size of equiaxed crystal is also conducted. ${ }^{11)}$ Figure 10 shows the comparison of calculated diameter of equiaxed grains with the observed ones in the cases with and without application of EMS. In the calculation, columnar dendrite growth rate and detachment of secondary arms of columnar dendrites of initial solid shell are modeled and the remelting or growth of the detached nuclei are simulated by analyzing the temperature and flow field in the liquid pool. It is demonstrated that application of EMS increases the number of detached nuclei and dissipates the super heat of the liquid pool and enlarge under cooled liquid region in the mold, which encourages the survival of detached nuclei. Both effects make the equiaxed grain size small.

\section{Conclusions}

Recent topics of research and development regarding major issues in continuous casting; nonmetallic inclusions, 
casting cracking and macrosegregation were discussed:

(1) By the application of in-mold EMS, nonmetallic inclusions with large diameter are eliminated from the surface layer of the casting. The flow velocity of $0.3 \mathrm{~m} / \mathrm{s}$ induced by EMS washes out inclusions larger than $100 \mu \mathrm{m}$ in diameter.

(2) By the application of LMF, the down stream velocity is much reduced and large inclusions and bubbles are eliminated from the inside of slabs, which otherwise cause inner defects in coils produced from the slabs.

(3) By the application of EMC, formation of hook mark, oscillation mark, surface depletion and longitudinal surface cracking are all prevented and hot scarfing of slabs can be eliminated.

(4) Unsteady slab bulging is resulted from the resonance with mold level oscillation. Unequally spaced support roll arrangement and intensive cooling are its counter measure.

(5) Since macrosegregation is caused by solute enriched residual liquid flow induced by thermal contraction and solidification shrinkage, proper amount of soft reduction of casting, which exactly compensates them, is a solution. Preferentially fine, equiaxed crystal structure is also a condition to moderate macrosegregation problem in the case of bloom.

\section{Acknowledgements}

EMC has been developed as electromagnetic casting project of JRCM, which is financially supported by Ministry of Economy, Trade and Industry of Japan

\section{REFERENCES}

1) W. Yamada, T. Matsumiya, S. Fukumoto, S. Tanaka and H. Takeuchi: Proc. Int. Conf. on Computer-assisted Materials Design and Process Simulation, ISIJ, Tokyo, (1993), 123.

2) J. Takamura and S. Mizoguchi: Proc. 6th Int. Iron Steel Cong, ISIJ, Tokyo, (1990), 591.

3) K. Ayata, K. Miyazawa, E. Takeuchi, N. Bessho, H. Mori and H. Tozawa: Proc. 3rd Int. Symp. on Electromagnetic Processing of Materials, ISIJ, Tokyo, (2000), 376.

4) T. Matsumiya: Innovation and Excellence in Continuous Casting, ed. by H. Marti, STAHL EISEN, Düsseldorf, (2003), 43.

5) W. Yamada, A. Kiyose, J. Nakashima, J. Fukuda, K. Okazawa and K. Miyazawa: CAMP-ISIJ, 12 (1999), 682.

6) H. Yamamura, T. Toh, H. Harada, E. Takeuchi and T. Ishii: ISIJ Int., 41 (2001), 1229.

7) T. Matsumiya, T. Saeki, J. Tanaka and T. Ariyoshi: Tetsu-to-Hagané, 68 (1982), 1782.

8) M. Tani, H. Harada, H. Toh, N. Yamasaki, K. Fujisaki, E. Anzai, E. Takeuchi, T. Matsumiya and K. Miyazawa: Proc. of 4th European Continuous Casting Conf., IOM Communication Ltd, London, (2002), 39.

9) T. Matsumiya: Mater. Trans., JIM, 33 (1992), 783.

10) S. Shima, Y. Maruki, J. Nakashima, H. Yamamura and Y. Oka: Proc. 2nd Int. Conf. on Process Development in Iron and Steelmaking (SACANMET II), Vol. 2, MEFOS, Lurea, (2004), 19.

11) H. Harada, K. Miyazawa, T. Matsumiya, T. Morohoshi and H. Esaka: Tetsu-to-Hagané, 89 (2003), 265. 